\title{
Understanding In-service Reading Teacher Efficacy
}

\author{
Barbara Wissink \\ Correspondence: Barbara Wissink, Concordia University- St. Paul, 1282 Concordia Ave, St. Paul, MN 55013, USA.
}

Received: August 25, 2019

doi:10.11114/ijce.v2i2.4529

\author{
Accepted: September 15, 2019 \\ Online Published: September 18, 2019
}

URL: https://doi.org/10.11114/ijce.v2i2.4529

\begin{abstract}
The complex task of teaching students to read well is one that in-service elementary teachers may not feel fully prepared for, as the methods for teaching reading have changed significantly in the last decade. As the research on explicit literacy instruction continues to expand, today's teachers require specific training on how to effectively teach reading and move beyond the traditional basal reading curriculum. Additionally, the research showed that a teacher's self-efficacy was a contributing factor in the actual implementation of new literacy instruction knowledge. This mixed method study examined the varying levels of self-efficacy from 36 in-service elementary reading teachers who were enrolled in a literacy education graduate program. The data suggested that in-service elementary reading teachers' self-efficacy fluctuated greatly due to additional professional development, administration support, and their years of teaching experience. Understanding how these components impacted an in-service reading teacher's self-efficacy was important, as previous research has shown that the level of teacher efficacy may have an impact on the effectiveness of their reading instruction and their students' literacy achievement in the elementary classroom.
\end{abstract}

Keywords: in-service teacher, self-efficacy, reading instruction, literacy

\section{Understanding In-Service Reading Teacher Efficacy}

In today's school climate of high accountability, elementary teachers are faced with the important task of developing skilled and motivated readers who are able to navigate and make meaning of various types of text. In order to accomplish this task, teachers need content knowledge in reading instruction. Additionally, the research has shown that teachers with a high level of efficacy in the area of literacy instruction were more committed to providing effective research-based reading instruction, and were more likely to stay in the teaching profession (Skaalvik \& Skaalvik, 2007; Ware \& Kitsantas, 2007). In response to this research, many preservice teacher education programs have intentionally scaffolded literacy instruction with accompanied field experiences in school settings in order to build teacher candidates content knowledge and teacher efficacy (Ciampa \& Gallagher, 2018). Preservice teacher programs have also designed specific field experiences that included observation and literacy tutoring tasks that are intentionally scaffolded to build pre-service teachers' efficacy in the area of reading instruction (Haverback \& Parault, 2011).

Yet, it is also important to examine and understand in-service teachers' self-efficacy, as perceptions of their ability to effectively teach reading may also impact their reading instruction and student achievement in the elementary classroom. For many experienced reading teachers, it is often assumed that their level of teacher self-efficacy is strong. However, Clark (2016) found that in-service teachers with at least one year of experience reported feeling less self-efficacy in several areas of reading instruction.

In many Midwestern school districts, in-service teachers have opportunities to engage in job-embedded coaching and professional development workshops in the field of literacy education to build their content knowledge of current literacy practices. Yet, in spite of the additional professional development and literacy coaching to enhance teachers' content knowledge, an in-service reading teacher's self-efficacy may not increase as a result of this training. Therefore, it is important to examine the various facets that construct a teacher's sense of self-efficacy as related to reading instruction.

The possibility of an imbalance between the in-service reading teachers' content knowledge and self-efficacy led to the following research question: Which factors contribute to an in-service teacher's level of self-efficacy for teaching reading? The purpose of this study was to examine in-service elementary literacy teachers' perceptions of their abilities to effectively teach reading, and determine the contributing factors in order to enhance in-service reading teacher efficacy in the future. 
The theoretical framework is based on Bandura's (1997) foundational socio-cognitive theory proposed the construct of self-efficacy and its impact on an individual's ability to achieve desired outcomes. Self-efficacy is the individual's belief in their competency and ability to achieve goals in a particular area. As in-service teachers gain expertise through the daily experience of working with children and the wide variety of literacy instructional strategies and curriculums, their sense of teacher-efficacy, or belief in their teaching abilities increases, resulting in more confidence in the classroom setting. Bandura (1993) adds that "teachers who lack a secure sense of instructional efficacy show weak commitment to teaching and spend less time on academic matters" (p. 134). Therefore, an in-service reading teacher with lower level of self-efficacy may result in less effective reading instruction which would impact students' literacy achievement.

With the increased accountability for student achievement in the last decade, especially in the area of reading, in-service teachers appear to need a strong sense of teacher-efficacy (TE) if they are to make a positive impact on student learning. Self-efficacy in teachers is often referred to as teacher efficacy. Abernathy-Dyer, Ortlieb, and Cheek (2013) define teacher efficacy as "a type of self-efficacy that can be distinguished from related constructs such as outcome expectancy, locus of control, and self-concept. TE measures the extent to which teachers believe efforts will have a positive effect on student achievement" (p.3). Without a strong belief in their effectiveness as a reading teacher, the teacher's reading instruction may not support student learning when compared to a reading teacher who has high teacher efficacy.

In addition to sufficient literacy content knowledge, the reading teacher's self-efficacy is an important construct to understand as it impacts the effectiveness and implementation of literacy instruction in the elementary classroom. Therefore, examining and understanding which factors constitute a strong sense of teacher efficacy for the teaching of reading is vital if today's teachers are to positively enhance students' literacy achievement.

\section{Review of the Literature}

The demand for highly qualified teachers, as referenced in the No Child Left Behind Act of 2001 (NCLB) called for states to ensure that each public school classroom was led by a teacher who was deemed highly qualified to teach the core subjects no later than the 2005-2006 school year (U.S. Department of Education, 2001, Section 1119). As reading is considered a core subject for teachers at the elementary level, the bar was raised for in-service elementary teachers. The need for professional development in the area of reading was also intensified in the beginning of the $21^{\text {st }}$ century by the expansive new research on literacy instruction, which was propelled by the National Reading Panel (NRP) Report that was published in the year 2000. In NRP report, the panel examined the literature on teacher education in reading instruction, and found that "there is a growing body of research that shows correlations between aspects of formal teacher preparation and quality of teaching or student outcomes" (National Reading Panel. 2000, p.5-3). The panel also examined research studies on the effects of professional development for in-service teachers, and found only 11 studies that measured student outcomes and teacher change (National Reading Panel, 2000, p. 5-7).

Teacher change for in-service teachers is often the result of attending the professional development seminars offered through the school district in which they are employed. To heed this call for highly qualified teachers with knowledge of the research-based literacy practices, many teachers reported in the RAND study that they felt the need to learn about research-based instructional practices, due to their state's increased accountability system under NCLB (Hamilton et al., 2007). This heightened sense of inadequate pedagogy in the area of literacy caused teachers to question their own effectiveness as teachers, and may have caused the downward spiral of their self-efficacy as professional educators.

Abernathy-Dyer et al. (2013) examined the teacher efficacy of four first grade teachers from different schools through a qualitative ethnographic case study, as they were engaged in changing their reading instruction to meet the new NCLB mandates. Two teachers were employed at Reading First schools, and the other two teachers were employed at non-Reading First schools. Each type of school implemented the new literacy programming through different approaches. Throughout this implementation, the four teacher-participants responded to a questionnaire, and were observed in their classrooms while implementing a new literacy curriculum. Abernathy-Dyer (2013) reported that the participants were all "committed to restructuring their instructional practices....the non-Reading First teachers felt as if they were being told to do the program with minimal say or support....and dramatic changes in their practice left many unanswered questions" (p.8). This study's findings suggested that a lack of support and professional development during the implementation phase of new literacy instructional strategies may lead teachers to feel inadequate and result in lower teacher efficacy, compounded by low student achievement.

A recent study conducted by Varghese, Garwood, Bratch-Hines, and Vernon-Feagans (2016) examined how kindergarten and first grade teachers' efficacy was influenced through the use of Targeted Reading Intervention (TRI), which is a web-based professional development coaching model that focuses on how to provide one-on-one reading interventions to struggling readers. The TRI professional development model was selected due to the limited opportunities for in-service teachers to receive literacy instruction in a rural school district. The participants were divided into an intervention group and a control group. The intervention group that received the TRI web-based 
coaching model consisted of 44 teachers and a total of 383 kindergarten and first grade students. The control group consisted of 32 teachers and a total of 235 kindergarten and first grade children. The aim of the one year study was to determine if the rural early elementary teachers' efficacy was impacted by the TRI web-based coaching model, and how the changes may have resulted in gains in literacy achievement for the struggling readers in the study.

In this study, Varghese et al. (2016) collected teacher efficacy data from the teachers through the completion of the Teacher Efficacy in Teaching Questionnaire (Tschannen-Moran \& Woolfolk Hoy, 2001) in the beginning and end of the school year. This questionnaire utilizes a five point Likert scale and measures teacher efficacy in three separate areas: classroom management, student engagement, and instructional quality. The literacy skills of the students in this study were assessed through the use of four subtests (spelling of sounds, word attack, letter-sound identification, and passage comprehension) within the Woodcock Johnson Diagnostic Reading Battery III (Woodcock, Mather, \& Shrank, 2004) during the fall and spring of the one year study.

Varghese et al. (2016) concluded that there was not a significant difference in the teacher's efficacy among the intervention and control groups in the three areas of classroom management, student engagement, or instructional quality, even though the teachers in the intervention group did include descriptive comments related to an increase in teacher efficacy. This finding implies that the TRI web-based coaching model on how to use reading interventions did not greatly impact the teacher-participant's efficacy as related to reading instruction. Interestingly, the researchers discovered that the classroom management component of the teacher efficacy questionnaire completed by the teachers who received the TRI web-based coaching provided the highest gains from the fall to spring. Varghese et al. (2016) surmised that a classroom environment with fewer distractions and interruptions related to student behavior may have led to a more focused implementation of the reading interventions strategies by the teachers in the intervention group, which were learned through the TRI professional development. The intervention teachers who had a high level of teacher efficacy in the area of classroom management on the teacher efficacy questionnaire, also had a significant increase of literacy skills for their students in the areas of letter-word identification, word attack, passage comprehension, and the spelling of sounds subtests (pp. 233-235). This study's findings supported the notion that at least one component of a teacher's sense of competency, or teacher efficacy, impacted the literacy achievement of students in the early elementary grades. The following study examined two possible underpinnings or facets of teacher efficacy as related to reading instruction: the teacher's attitude and reading habits.

Nathanson, Pruslow, and Levitt (2008) conducted a study to examine the affective domain of reading, and how teachers of reading may influence the reading behaviors of their students. In particular, the researchers were interested in determining a causal relationship between the teacher's aesthetic enjoyment of reading and their students' literacy growth. Their interest was based on "an earlier study (Mour, 1977) which found that only $25 \%$ of in-service teachers who were enrolled in a graduate program on reading instruction were considered enthusiastic readers" (as cited in Nathanson, Pruslow, \& Levitt, 2008, p. 314). The researchers in this study echoed the growing concern among researchers in the field of literacy about "the Peter Effect" (Applegate \& Applegate, 2004, p. 556), which refers to the Biblical story of the Apostle Peter who told the beggars that he could not give what he did not have. Nathanson et al. (2008) replicated the study conducted by Applegate and Applegate (2004) by administering the Literacy Habits Questionnaire (LHQ) to graduate students who were active, full-time teachers, and those who were the full-time graduate students pursing further education and not teaching. After a total of 747 completed questionnaires were analyzed, the findings indicated that only " $47 \%$ of the respondents characterized themselves as enthusiastic to highly enthusiastic readers....this is a sobering and unsatisfactory situation, which, we believe, could have negative implications for the literacy of future generations" (Applegate \& Applegate, 2004, p. 318). This study's findings suggested that teachers who do not consider themselves to be passionate about reading in their own lives, may not feel a strong sense of efficacy related to their reading instruction. This finding supports the need to examine reading teachers' efficacy and its underpinnings in order to strengthen future reading instruction.

The following study, conducted by the author and discussed in this paper, was aimed at uncovering facets that are underpinnings of a reading teacher's sense of competency or teacher efficacy, which may also impact the reading instruction that is delivered by an in-service teacher. The in-service elementary teachers who participated in this study were also graduate students in a reading instruction program at an urban university during the 2016-17 academic year. The graduate reading program consisted of five semesters of literacy courses, and lead the licensed in-service teachers towards the earning of a K-12 Reading Endorsement in a Midwestern state. Earning the K-12 Reading Endorsement required the successful completion of the graduate literacy coursework, and the passing of a state competency exam in the area of reading instruction. 


\section{Methods}

\subsection{Design}

The mixed method study consisted of an online survey, created by the author, which included a total of 10 questions that were quantitative and qualitative in nature in order to capture the abstract construct of teacher efficacy. Ponce and Pagan-Maldonada (2014) stated that the premise behind a mixed methods study in the field of education "is to integrate or intentionally combine quantitative and qualitative approaches as components of the study. The aim is to explore the complexity of the research problem to measure their objective aspects and to understand / describe their subjective elements as directly and accurately as possible towards its manifestation or expression" (p. 115). Within the survey utilized in this study, questions with structured response choices provided data that was quantitative in nature, while unstructured or open-ended questions provided qualitative data such as personal comments from the respondents. The survey measured the responses of in-service elementary teachers in the study, and provided quantitative data about their personal rating of self-efficacy in relation to reading instruction in their own classrooms. Several questions were intentionally designed to capture qualitative data, such as the keen insights about which factors or underpinnings contributed to their sense of competency or teacher efficacy rating, and how their efficacy fluctuated in response to literacy initiatives within their school settings. Therefore, the participants provided rich quantitative and qualitative data through the completion of the survey, which was coded and analyzed. The goal of this study was to enhance the understanding of the various underpinnings of teacher efficacy through the responses of the elementary reading teachers who participated in this study.

\subsection{Participants/Data Collection}

There was a total of 36 in-service elementary teachers $(\mathrm{N}=36)$ who participated in this study through the voluntary completion of a 10 question online survey. The elementary teacher participants were also graduate students in the Master of Arts: Curriculum and Instruction with K-12 Reading Endorsement program at an urban Midwestern university during the 2016-17 academic year. The participant selection was considered as a convenience sampling, as the 36 in-service teachers were enrolled in the graduate program focused on reading, and were selected to complete the survey, based on being an experienced, licensed teacher at the elementary level. Boudah (2011) notes that this type of sample of participants were "readily available to the researcher" (p. 166). Boudah (2011) also cautioned that convenience sampling results in data that is not generalizable to the population at large, which was later discussed as a limitation of this study. In spite of this inherent limitation in the sampling method, this unique group of in-service elementary teachers who volunteered as participants, had also self-selected to further their knowledge of reading instruction by enrolling in a graduate program, As the researcher in this study, it was deemed possible that the teacher self-enrollment in this particular graduate program may have been the result of a high or low level of teacher efficacy related to the teaching reading in their elementary classrooms, which led to a unique sample of participants.

The 36 participants in this study consisted of graduate students who were completing the literacy coursework through either a face-to-face or online cohort format at the university. Due to the two different course delivery formats, the survey was provided as a digital online link, which allowed all of the graduate students a consistent framework for voluntarily providing their responses. The online survey link was sent to 82 graduate students in the specific literacy program, and yielded a response rate of $43.9 \%$ when 36 complete surveys were submitted. This was a higher response rate than the expected average of $33 \%$ for online surveys, but was lower than the response rate of paper-based surveys, which average approximately 56\% (Nulty, 2008, p. 302).

Based upon the data from the completed surveys, the majority of the elementary teachers who participated in the study were female Caucasians (97.22\%, N=35), and had been teaching between four to six years (see Table 1). In addition, $45 \%$ of the teachers reported that they were teaching Kindergarten or first grade students during the time of this study, which was interesting to note, based on those are the specific grade levels that are highly focused on the teaching of reading.

Table 1. Number of years of teaching experience

\begin{tabular}{ccc}
\hline Answer choices & Responses $(\boldsymbol{\%})$ & N of Participants \\
\hline $1-3$ years & 8.33 & 3 \\
\hline 4-6 years & 41.67 & 15 \\
\hline 7-10 years & 25.00 & 9 \\
\hline 11-15 years & 13.89 & 5 \\
\hline 16-20 years & 2.78 & 1 \\
\hline 21 or more years & 8.33 & 3 \\
\hline
\end{tabular}

It was also interesting to note that of the 36 elementary teacher participants, nine participants responded that they were currently serving students as an elementary literacy coach or reading specialist. Yet, only seven of the 36 participants reported that they currently held a K-12 Reading Endorsement, which is considered a qualification for holding a literacy 
coach or reading specialist position in Midwestern public schools. This may indicate that the two participants who held literacy positions could be serving students in a charter or private school setting where the state licensing regulations are not enforced, or were hired with the requirement of obtaining the K-12 Reading Endorsement within a specific timeframe.

\subsection{Data Analysis}

The quantitative data about the participants in the survey was illustrated using frequency tables, and interpreted by the researcher based on the percentages of the responses. The questions in the survey that revealed qualitative data were coded using by concept categories (Boudah, 2011, p.230). These categories were formed as a result of containing similar descriptive responses to the unstructured, or open-response questions in the survey. The descriptive responses were also analyzed in order to reveal any cross-cutting themes between the categories. Further information of the analysis and interpretation of the findings are presented in the following section.

\section{Results}

When the in-service elementary teachers were asked in a structured response question to "reflect upon and rate their current level of self-efficacy and perception of competency in elementary reading instruction in their current grade level." The majority $(41.67 \%, \mathrm{~N}=15)$ of the participants reported that they felt "competent". Another $22.22 \%(\mathrm{~N}=8)$ felt "highly competent" teaching reading in their current grade level. The eight participants who stated feeling "highly competent" were also noted as reporting that they were currently in positions as literacy coaches or reading specialists and have seven to 10 years of teaching experience, which may account for their personal rating of high competency in the area of literacy instruction.

Interestingly, exactly one third of the in-service teachers $(33.33 \%, \mathrm{~N}=12)$ responded that they feel "somewhat competent" teaching reading in their current grade level, and most $(66.66 \%)$ of these respondents also reported that they had been teaching six or less years. A possible factor that may account for the feeling of "somewhat competent" may be related to a recent grade level change, as the survey question was focused on their perception of competency in reading instruction at their current grade level. Only one participant $(2.78 \%)$ responded that he/she did not feel competent teaching reading in their current grade level.

As a follow-up, unstructured question, the in-service teachers were asked "to describe which factors they believed have led them to their self-efficacy and perception of competency rating in the prior question." The following six categories emerged from their written responses to this question during the coding process, and are shown in Table 2 below. Due to one participant response including comments that fit in two categories, the total number of responses that were coded and categorized was 37 , even though there were 36 in-service elementary teachers who completed the survey. This result was due to one teacher responded that seeing "student growth" and receiving "professional development that reaffirms what I am doing" were both factors that contributed to a "highly competent" self-rating of her reading instruction.

Table 2. Categories of contributing factors to self-rating of competency in reading instruction

\begin{tabular}{l|c|c}
\hline Category of Contributing Factors to Competency & Responses (\%) & N of Participants \\
\hline $\begin{array}{l}\text { Extensive Professional Development } \\
\text { (Training, workshops, graduate coursework) }\end{array}$ & 41.67 & 15 \\
\hline $\begin{array}{l}\text { Lack of Professional Development } \\
\text { (Trainings, workshops, graduate coursework) }\end{array}$ & 25.00 & 9 \\
\hline $\begin{array}{l}\text { Positive Impact on Student Growth in Reading } \\
\text { (Formative and summative assessment results) }\end{array}$ & 11.11 & 4 \\
\hline $\begin{array}{l}\text { Time-related Factors in the School Day } \\
\text { (Limited prep-time, limited literacy block time) }\end{array}$ & 13.88 & 5 \\
\hline $\begin{array}{l}\text { Teaching Experience } \\
\text { (Several years at current or similar grade level) }\end{array}$ & 5.55 & 2 \\
\hline $\begin{array}{l}\text { Other Non-Related Factors } \\
\text { (Responses that did not fit in one of the } \\
\text { emergent categories above) }\end{array}$ & 5.55 & 2 \\
\hline
\end{tabular}


The participant responses (see Table 2) demonstrated that the majority $(41.67 \%, \mathrm{~N}=15)$ of in-service teachers tend to equate extensive professional development, such as trainings, workshops, and graduate coursework, as contributing to their self-efficacy and perception of competency in the area of reading instruction. Conversely, a lack of professional development was reported by one fourth $(25 \%, \mathrm{~N}=9)$ of the in-service teachers as a factor that contributed to their sense of less competency in the literacy classroom. Noting that only one teacher previously reported a sense of not being competent in the previous survey question results, it may be interpreted that these respondents only felt they were "competent". This assertion was supported by comments such as "I know that I still have a lot to learn, which is why I did not say highly competent" and "Getting my K-12 reading license was one of the best choices I ever made. Because of that, I feel competent to teach Title 1 . However, I am only in my $6^{\text {th }}$ year of teaching and I know I still have a lot to learn, which is why I did not say highly competent."

The 36 participants were also asked the following structured response question, "What could help you to feel more competent in your teaching of reading?" and were provided with five response choices, and the directions to rank the choices that apply in the order of importance. The response ranked as the most important by 10 in-service teacher participants was "coaching or mentoring by a building or district reading specialist." The second highest ranked response by eight participants was "additional graduate coursework through a college or university". Due to the convenience sample of participants in this study, these highly ranked responses were not a surprise, as the respondents were all graduate students who were completing coursework in a program that lead to earning the K-12 Reading Endorsement in a Midwestern state. However, the response that was ranked the lowest by the participants was not expected. The in-service teachers ranked "Professional Learning Committee (PLC) focused on literacy" as the least important component that could increase their sense of self-efficacy or perception of competency in the teaching of reading. This common job-embedded practice in schools was not considered to be as effective as the other four professional development opportunities provided as choices in this particular survey question, which may lead administrators to reconsider this type of professional development offering.

The teachers were also asked to "reflect and select which of the following factors have contributed to a feeling of inadequacy in their current teaching of reading, or in the past years." The participants were provided the directions to select all that apply and rank their choices in order of importance. Interestingly, of the six structured responses, the one response that 13 teachers ranked as the highest factor that lead to a feeling of inadequacy in the teaching of reading was "new reading programs or initiatives that lacked sufficient professional development." These 13 teachers also responded earlier that they have taught six or less years, which may have influenced their response to this question, as teachers with more years of experience have most likely experienced teaching from more than one reading curriculum or framework. The second highest factor was the "transition to a new grade". This response was not unexpected, as each of the elementary grades focus on teaching to the unique developmental needs of the readers in the grade level. Teachers who are asked by the administrator to teach a different grade level would need time to acclimate to the instructional focus within the reading program at the new level.

The amount of administrator or principal support was also reported to be a factor that impacted the in-service elementary teachers' self-efficacy for reading instruction. When the participants were asked to describe "how does the support of the building principal or administration impact your self-efficacy for reading instruction in the elementary classroom?" the participants' unstructured responses were coded and categorized into the following areas in Table 3 below.

Table 3. Administrator/principal's impact on elementary teachers' reading instruction

\begin{tabular}{lcc}
\hline \multicolumn{1}{c}{ Category of impact } & Responses (\%) & N of Participants \\
\hline Positive influence & 33.33 & 12 \\
\hline Negative influence & 36.11 & 13 \\
\hline Neutral influence & 11.11 & 4 \\
\hline Non-related response & 19.44 & 7 \\
\hline
\end{tabular}

Many of the teacher responses to this unstructured question clearly demonstrated that they had experience with an administrator that positively $(33.33 \%)$ or negatively $(36.11 \%)$ influenced their self-efficacy for reading instruction in their elementary classroom. Positive comments such as "they have encouraged literacy coaches to push into the classroom, paid for extra professional development, and given support when needed" were closely matched by negative comments such as "the building principal is not an expert in teaching reading, and offers reading suggestions that go against best practice." and "The administration gives a very broad overview, but there isn't anyone who knows about elementary literacy". Compounding the lack of a clear distinction of administration support were the seven responses 
that appeared to be unrelated to the question posed. Examples of unrelated responses included "no idea" or "n/a", which could reveal that this question was not clear for approximately $19 \%$ of the participants. Additionally, four responses were categorized as a neutral influence, when they listed both a positive and a negative influence on their self-efficacy for teaching reading.

Lastly, the in-service teachers were asked "to reflect and describe one area of reading instruction that they would like to improve on during the next 12 months." The purpose of this unstructured question was to determine possible areas of instructional weakness, which could have led to their previous self-rating of their competency and self-efficacy and their overall perception of competency for teaching reading. The in-service teachers' responses were coded and categorized as Areas for Improvement (AFI) as shown in Table 4 below.

Table 4. Areas for improvement in elementary teachers' reading instruction

\begin{tabular}{lcc}
\hline Category of AFI & Response \% & N of Participants \\
\hline Guided Reading & 8.33 & 3 \\
\hline Vocabulary Instruction & 11.11 & 4 \\
\hline Intervention Strategies & 11.11 & 4 \\
\hline Phonological and Phonemic & & \\
Awareness Instruction & 5.55 & 2 \\
\hline Comprehension Strategies & 5.55 & 2 \\
\hline Other AFI & 58.33 & 21 \\
\hline
\end{tabular}

Based upon the coding and categorizing of the responses to this unstructured question, the majority of the participants $(58.335, \mathrm{~N}=21)$ described specific areas for improvement that were unique to their individual content or pedagogical knowledge, or related to their individual school's initiatives and therefore were placed in the "other" category as shown in the table above. Examples of these non-categorized responses included knowledge of a specific curriculum, such as "learning more about Words their Way", or personal teaching goals such as "I am working on designing instruction using the backwards design process and essential questions." Therefore, this demonstrated that this question was not able to determine one or two major areas of reading instruction that a significant number of the participants felt they needed additional support or training in during the next 12 months. This data may also be interpreted as the in-service elementary teachers had specific instructional needs based on their school context, as some responses stated "we have a high English Language Learner population", or a "there's a need for specific reading knowledge" which may be the result of the teachers' unique school student population. The responses to this question indicated that there are a variety of reasons why teachers feel the need to improve their reading instruction and that professional development and trainings should be determined by the specific needs of the teachers.

\section{Discussion}

The 36 in-service elementary teachers' survey responses showed that the level of self-efficacy for the teaching of reading was impacted by several factors. A few commonly predicted factors were shown to have an impact on an in-service reading teacher's self-efficacy, such as the number of years of experience teaching reading, and the amount of professional development in the area of literacy. Additionally, the specific context of the school, such as a high English Language Learner (ELL) population was noted as a factor that may have contributed to a decrease in the reading teacher's self-efficacy due to a lack of professional development on teaching reading to ELLs.

A new literacy program, with limited professional development support, and a transition to a new grade level were noted as contributing factors to a lower level of self-efficacy or perception of competency for teaching reading. Additionally, the teachers noted that their sense of a lack of administration understanding, knowledge, or support for literacy instruction also were contributing factors to an in-service reading teacher's self-efficacy. These factors are important to note when administrators or literacy coachers are planning future teacher classroom transitions and literacy professional development support that accompanies new curriculum initiatives, as they were shown to impact teacher efficacy for teaching reading.

\section{Limitations}

The major limitations of this study are related to the use of convenience sampling, a small number of participants, and the clarity or format of two specific questions in the survey as noted earlier. The survey sample consisted of a readily available group of in-service elementary teachers who were enrolled in a graduate program focused on literacy. The 
literacy coursework led the teachers to earning a K-12 Reading Endorsement in the Midwestern state where they resided. The teachers who volunteered to complete the online survey had already self-selected a graduate literacy program to further their instructional and career goals. This unique set of participants' responses cannot be generalizable, though they provided some keen insights on their sense of competency or teacher efficacy in the area of reading instruction.

This study consisted of 36 elementary in-service teachers, which is considered a small sample size in a mixed method educational research study. Due to the small number of participants, the results are not generalizable to elementary teachers who teach reading. The results of two specific questions in the survey also yielded data that was not beneficial in providing a clear lens of how their reading instruction was impacted by various factors.

When the teachers were asked "how does the support of the building principal or administration impact your reading instruction in the elementary classroom?" the responses were not able to clearly identify a few key areas of support that their administration provided that impacted their literacy instruction. Rather, this question resulted in a similar percentage of positive and negative responses about their individual administration or principal, which was not the intent of the unstructured response question. Similarly, another unstructured survey question yielded a broad spectrum of individualized responses that were not beneficial in shedding light on "one area of reading instruction" that they would like to improve on during the next 12 months. Over half $(56.33 \%)$ of the 36 participants in the study responded with individualized responses that were not able to be categorize during the coding process due to being unlike other responses to that specific question.

\section{Implications and Future Research}

A few implications can be derived from the data resulting from this study. One implication is that the majority of in-service teachers, who self-selected to enroll in a graduate program focused on literacy and participate in this study, were teachers with four to six years of teaching experience. This information may be useful for administrators who need to identify teachers within this range of teaching experience and graduate coursework, and utilize them as mentors for new teachers who are in need of additional support in the area of reading instruction.

Another implication resulting from this study is the understanding that administrators and principals do have an important role in how elementary teachers deliver reading instruction in the district and/or building. The majority of elementary teachers $(69.44 \%)$ clearly identified that their administrator or principal had a positive or negative impact on their self-efficacy for classroom reading instruction. This information may lead administrators to survey their teachers in order to understand how administrative support influences their daily classroom literacy practices, and use that data to remedy or enhance the reading teachers' sense of efficacy.

A third implication from this study is in the area of individual teacher perceptions of self-efficacy and specific areas for improvement in their reading instruction. While the majority of the responses were individualized, this leads to the insight that in-service elementary teachers do have varying levels of self-efficacy for teaching reading, and they may benefit greatly from professional development targeted on their specific needs for enhancing their reading instruction. For administrators, curriculum coordinators, and literacy specialists, this data reveals that the selection of the professional development topics may not be as simple or as clear as offering a "one size fits all" workshop. Rather, this information may yield the opportunity for teachers to self-select the professional development topics specific to reading instruction from a specialized "menu" of workshops or courses each year, which may result in a higher sense of instructional competency or teacher efficacy within their faculty members.

\section{Conclusion}

This study focused on examining 36 experienced elementary teachers' perceptions of self-efficacy as related to their reading instruction, and the factors that influenced the variations of a teacher's sense of competency or teacher efficacy in the area of literacy instruction. The participants were graduate students at an urban university in the Midwest. The teachers had self-selected a graduate program focused on literacy instruction, and which led to the earning of a K-12 Reading Endorsement in their state. The convenience sample of in-service elementary teachers, who were also graduate students interested in improving or enhancing their literacy practices, does not allow the results to be generalizable. Yet, the insights gathered from their voluntary responses to questions on an online survey, can inform administrators and district leaders on the needs of their faculty as related to supporting a strong teacher efficacy for teaching reading in the elementary classroom.

In the age of high-stakes testing of student literacy growth, school administrators may benefit from the honest perceptions and responses from the in-service elementary teachers who participated in this study. As one veteran teacher in this study stated, " the principal guides what areas of literacy instruction we put most of our focus towards", which was echoed by another in-service teacher who commented, "the principal can positively impact reading instruction by the time necessary to evaluate what's happening in the classroom as compared to their expectations, analyzing data, 
being involved in teacher PLCs that analyze the data and discuss instruction, and by being an instructional leader" in the school community.

The in-service elementary teachers in this study have demonstrated differing perceptions of their efficacy and perceived competency as reading teachers, and have identified a wide variety of professional development needs that can be positively impacted by the decisions and actions of the administration. These critical decisions can lead to improved literacy instruction in the elementary classroom, which could lead to an increase in students' reading proficiency. This chain reaction can be best summarized as "effective education leadership makes a difference in improving learning....What's far less clear, even after several decades of school renewal efforts, is just how leadership matters, how important those effects are in promoting the learning of all children" (Leithwood, Seashore Louis, Anderson \& Wahlstrom, 2004, p. 3). The voices of the 36 elementary teachers in this study, who are striving for a higher level of self-efficacy through administrative support, effective professional development, and research-based literacy content knowledge through their continued studies in graduate school need to be heard if promoting children's literacy is truly valued by educational leaders across the K-12 school system.

\section{References}

Abernathy-Dyer, J., Ortlieb, E., \& Cheek, E. H. (2013). An analysis of teacher efficacy and perspectives about elementary literacy instruction. Current Issues in Education, 16(3), 1-12. https://cie.asu.edu/ojs/index.php/cieatasu/article/viewFile/1290/522

Applegate, A., \& Applegate, M. (2004). The Peter Effect: Reading habits and attitudes of preservice teachers. The Reading Teacher, 57, 554-563. Retrieved from http://www.jstor.org/stable/20205399

Bandura, A. (1993). Perceived self-efficacy in cognitive development and functioning. Educational Psychologist, 28(2), 117-148. https://doi.org/10.1207/s15326985ep2802_3

Bandura, A. (1997). Self-efficacy: The exercise in self-control. New York, NY: The W.H. Freeman Company.

Boudah, D. J. (2011). Conducting educational research: Guide to completing a major project. Thousand Oaks, CA: Sage Publications. https://doi.org/10.4135/9781483349138

Ciampa, K., \& Gallagher, T. L. (2018). A comparative examination of American and Canadian pre- service teachers' self-efficacy beliefs for literacy instruction. Reading and Writing: An Interdisciplinary Journal, 31(2), 457-481. https://doi.org/10.1007/s11145-017-9793-6

Clark, S. (2016). An exploratory study examining the influence of the number of reading methods courses on pre-service and in-service teacher perceptions of ability to teach reading. Asia- Pacific Journal of Teacher Education, 44(2), 125-141. https://doi.org/10.1080/1359866X.2015.1066492

Hamilton, L. S., Stecher, B. M., Marsh, J. A., McCombs, J. S., Robyn, A., Russell, J. L., ... Barney, H. (2007). Standards-based account- ability under No Child Left Behind: Experiences of teachers and administrators in three states. Santa Monica, CA: RAND. https://doi.org/10.7249/MG589

Haverback, H. R., \& Parault, S. J. (2011). High efficacy and the preservice reading teacher: A comparative study. Teaching and Teacher Education, 27(4), 703-711. https://doi.org/10.1016/j.tate.2010.12.001

Leithwood, K., Seashore, L. K., Anderson, S., \& Wahlstrom, K. (2004). Review of research: How leadership influences student learning. New York, NY: The Wallace Foundation. http://www.wallacefoundation.org/knowledge-center/Documents/How-Leadership-Influences-Student-Learning.pdf

Nathanson, S., Pruslow, J., \& Levitt, R. (2008). The reading habits and literacy attitudes of in-service and prospective teachers. Journal of Teacher Education, 59(4), 313-321. https://doi.org/10.1177/0022487108321685

National Reading Panel (U.S.), \& National Institute of Child Health and Human Development (U.S.). (2000). Report of the National Reading Panel: Teaching children to read: An evidence-based assessment of the scientific research literature on reading and its implications for reading instruction: Reports of the subgroups. Washington, D.C.: National Institute of Child Health and Human Development, National Institutes of Health.

Nulty, D. D. (2008). The adequacy of response rates of online surveys to paper-based surveys: What can be done? Assessment \& Evaluation in Higher Education, 33(3), 301-314. https://doi.org/10.1080/02602930701293231

Ponce, O., \& Pagan-Maldonada, N. (2015). Mixed methods research in education: Capturing the complexity of the profession. International Journal of Educational Excellence, 1(1), 111-135. https://doi.org/10.18562/IJEE.2015.0005

Skaalvik, E. M., \& Skaalvik, S. (2007). Dimensions of teacher self-efficacy and relations with strain factors, perceived collective teacher efficacy, and teacher burnout. Journal of Educational Psychology, 99(3), 611-625. 
https://doi.org/10.1037/0022-0663.99.3.611

Tschannen-Moran, M., \& Woolfolk, H. A. (2001). Teacher efficacy: Capturing an elusive construct. Teaching and Teacher Education, 17, 783-805. https://doi.org/10.1016/S0742-051X(01)00036-1

U.S. Department of Education. (2001). No Child Left Behind Act of 2001. Retrieved from https://www.congress.gov/bill/107th-congress/house-bill/1

Varghese, C., Garwood, J. D., Bratch-Hines, M., \& Vernon-Feagans, L. (2016). Exploring magnitude of change in teacher efficacy and implications for students' literacy growth. Teaching and Teacher Education, 55, 228-239. https://doi.org/10.1016/j.tate.2016.01.011

Ware, H., \& Kitsantas, A. (2007). Teacher and collective efficacy beliefs as predictors of professional commitment. The Journal of Educational Research, 100(5), 303-310. https://doi.org/10.3200/JOER.100.5.303-310

Woodcock, R. W., Mather, N., \& Schrank, F. (2004). Woodcock Johnson III Reading Diagnostic Battery. Riverside, IL: Rolling Meadows.

\section{Copyrights}

Copyright for this article is retained by the author(s), with first publication rights granted to the journal.

This is an open-access article distributed under the terms and conditions of the Creative Commons Attribution license which permits unrestricted use, distribution, and reproduction in any medium, provided the original work is properly cited. 